\title{
Medicinal Herbs and Epilepsy: A Two Edged Sword
}

\author{
Mahyar Janahmadi, Sahar Farajnia, Zahra Ghasemi and Ali Rastqar \\ Neuroscience Research Centre and Department of Physiology, Medical School \\ Shahid Beheshti Medical Sciences University, Tehran
}

Iran

\section{Introduction}

Epilepsy is one of the most serious neurological disorders affecting about $0.5-1 \%$ of the world population. There is no definite radical therapy against epilepsy; however, actual therapy includes simple inhibition of epileptic activity. Apart from effective drugs against epilepsy, plant extracts as well as essential oils, which have been used for generations by humans to treat the disease, are considered nowadays as potential bioactive agents that can interfere and alter cellular physiological processes involved in epileptogenesis. However, the exact underlying mechanisms and the electrophysiological consequences of action of most medicinal herbs are still not known.

Recently, we have reported that the essential oil of Anise, Pimpinella anisum L. (Apiaceae), which is one of the oldest known and highly used spice plants in the folk medicine, causes hyperexcitability at the cellular level and changes the neuronal firing pattern from a regular tonic discharge to an irregular and then to bursting mode in normal cells or potentiates the burst firing and the steepness of the paroxysmal shift induced by PTZ treatment (Janahmadi et al., 2008). However, we have also shown that some herbs, including Cuminum cyminum (Janahmadi et al, 2006) and Artemisia drancunculus (Farajnia et al., 2011), can inhibit the epileptiform activity induced by PTZ, a well known convulsant agent. This sort of contradictory effect of herbal essential oils and extracts is one reason why a certain caution is needed when medicinal herbs are used to treat patients suffering from epilepsy. The present work is focused on comparison of the electrophysiological consequences of essential oil and extract of Tarragon on PTZ-induced neuronal hyperexcitability in snail for the first time. In addition, the effect of anethole, the chief ingredient of many aromatic herbs, including anise and tarragon, on normal neuronal excitability is also tested.

Tarragon or dragon's-wort (Artemisia dracunculus) is a perennial herb in the family Asteraceae related to wormwood that exerts radical-scavenging activities (Parejo et al., 2002), antifungal and antitumor effects (Zani et al., 1991; Meepagala et al., 2002) and antiepileptic activities (Sayyah et al., 2004; Farajnia et al., 2011). In Iranian traditional medicine, the dried aerial parts of this plant were mentioned as a treatment for epilepsy (Aqili Khorasani, 1992). The composition of the essential oil of Iranian A. dracunculus was reported to include trans-anethole and a-trans-ocimene as the major constituents $(21.1 \%$ and $20.6 \%$, respectively). More recently, we demonstrated the dual effects of anethole on $\mathrm{Ca}^{2+}$ dependent excitability in snail neurons: at low concentration anethole caused a significant 
reduction in the firing frequency and enhancement of AHP amplitude, but at high concentration it significantly increased the firing frequency and also decreased the AHP amplitude (Ghasemi et al., 2011). Anethole (1-methoxy-4-(1-propenyl)-benzene), which is largely used in industry as a flavor or as a odorant, possess several potential pharmacological activities such as depressive action on motor system (Boissier et al., 1967), anticarcinogenic (Al-Harbi et al., 1995), antioxidant (Freire et al., 2005), anti-inflammatory, (Chainy et al., 2000) and anesthetics activity (Ghelardini et al., 2001). It was suggested that some of the essential oils (e.g. anise) containing monoterpenoids especially trans-anethole exert anticonvulsant activity (Sayyah et al., 2004). Pimpinella anisum is another aromatic herb which contains anethole as its main constituent. Anise is native to the eastern Mediterranean and is a plant rich in volatile oils, which are employed in traditional Asian folk medicine. Water and ethanol extracts of Pimpinella anisum seed have several potent therapeutic effects including antioxidant and antimicrobial activities (Gülçin et al., 2003). The essential oil of anise has also been reported to exert both fungicidal and antibacterial actions (Soliman and Badeaa, 2002; Singh et al., 2002) and anticonvulsant activity (Pourgholami et al., 1999). In contrast, we have recently shown that the essential oil of anise produces neuronal hyperexcitability and potentiates PTZ-induced epileptiform activity in snail by enhancing the $\mathrm{Ca}^{2+}$ channels activity or inhibition of voltage and /or $\mathrm{Ca}^{2+}$ dependent $\mathrm{K}^{+}$channels function (Janahmadi et al., 2008). We believe that this effect might be due to anethole, the chief constituent of the essential oil of anise. Thus, the main aims of this study are: (1) to compare the electrophysiological effect of Tarragon extract with that of its essential oil, (2) to test the cellular effect of anethol on neuronal excitability, using intracellular recording method under current clamp condition.

\section{Materials and methods}

Electrophysiological recording was performed on the soma membrane of neurons from suboesophageal ganglia of Helix aspersa (Iranian garden snail). The snail brain consists of a circum-oesophageal ring of nine ganglia. Two are dorsal supra-esophageal (the cerebral ganglia) and the remaining seven constitute the suboesophageal ganglia (Kerkut et al., 1975). Snail neurons are often large and located peripherally. It is therefore possible to work on a specific neuron from on preparation to another because they can be consistently identified on the basis of their size and location. In the present study, we will focus on F1, the largest neuron located in right parietal ganglion (Fig.1).

Adult Iranian garden snails were collected from north of Iran and were kept in a dormant state until they were used. The day before experimentation, animals were activated by wetting and then they were anaesthetized by injecting them with $2 \mathrm{ml}$ of $50 \mathrm{mM} \mathrm{MgCl}_{2}$. The shell was removed with bone forceps and the snail with its head extended was pinned out on a cork board. Next, the circum-oesophageal ganglia were removed from the animal, keeping the nerves and aorta attached to the ganglia as long as possible. Then, the ganglionic mass with its main peripheral nerves and aorta was placed in a recording chamber, lined with Sylgard 170 (Dow corning Midland, MI, USA) containing normal snail Ringer solution (in $\mathrm{mM}$ ): $\mathrm{NaCl} 80, \mathrm{KCl} 4, \mathrm{CaCl}_{2} 10, \mathrm{MgCl}_{2}$ 5, Glucose 10, Hepes 5 (Taylor, 1987). In order to expose F1 neuron, the connective tissue overlying the ganglia were gently torn using two pairs of fine forceps without any pre-treatment with proteolytic enzymes. F1 cell was visually identified by its size, color and location within the right parietal ganglion (Kerkut et al., 1975). These procedures were in accordance with the guidelines of the Institutional Animal Ethics Committee at Shahid Beheshti University of Medical Sciences. 


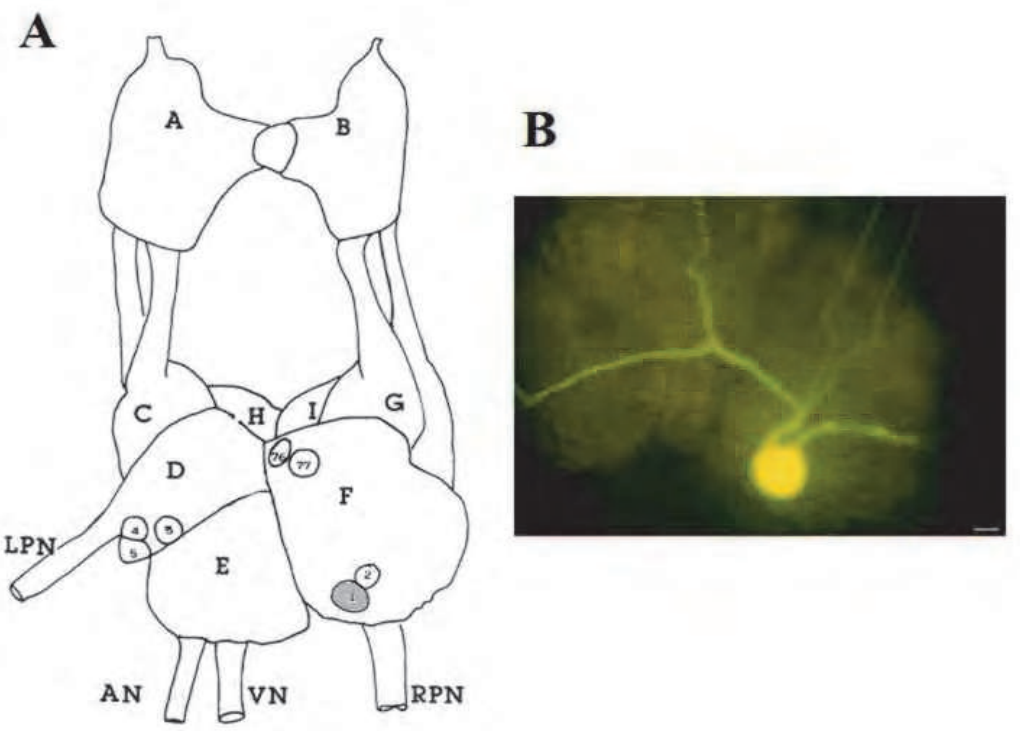

Fig. 1. (A) Scheme redrawn from Kerkut et al. (1975) showing the nine ganglia of the $H$. aspersa circum-oesophogeal ganglia and the four main peripheral nerves. The cell body of F1 (in grey colour) is located in the RPG ( $A$ left cerebral ganglion, $B$ right cerebral ganglion, $C$ LPIG, D LPG, E VG, F RPG, G RPlG, $H$ left pedal ganglion, I right pedal ganglion, LPN left pallial nerve, $R P$ right pallial nerve, $V N$ visceral nerve, $A N$ anal nerve). (B) F1 neuron was stained intracellularly by the injection of Lucifer Yellow (5nA hyperpolarizing current pulses of $500 \mathrm{~ms}$ duration).

\subsection{Intracellular electrophysiological recording}

Sharp intracellular recording was done using Axoclamp 2B amplifier (Axon instrument, Foster City, CA, USA) at room temperature $\left(22-25^{\circ} \mathrm{C}\right)$ in snail Ringer. Each cell was impaled with single electrode $(5-7 \mathrm{M} \Omega)$. Electrode was filled with $3 \mathrm{MKCl}$ and in some cases with Lucifer Yellow. The reference electrode in all experiments was a silver-silver chloride wire within an agar bridge (\%4 agar in snail Ringer). The above set-up and recording equipment were kept in a Faraday's cage.

Intrinsic spontaneous neuronal activity was recorded under conventional current clamp in real time by testing, before (control), and after application of drugs. Five sets of experiments were done. The first and second sets of experiments were conducted in order to examine the cellular and antiepileptic effects of essential oil of Tarragon alone or on the PTZ-induced epileptiform activity, respectively. In the third and fourth sets of experiments, the cellular and antiepileptic actions of Tarragon extract alone or against the epileptogesis induced by PTZ were assessed, respectively. The sixth set of experiment was performed to evaluate the electrophysiological effect of anethole on normal neuronal excitability in snail. Data were filtered at $30 \mathrm{kHz}$, voltage records were sampled at $20 \mathrm{kHz}$ and digitized online using a 16 bit A/D converter (ADInstrument Pty Ltd., Sydney, Australia) and stored for further analysis using Chart 5 and MATLAB softwares. The following electrophysiological parameters of spikes were considered in particular: The firing pattern, the firing frequency, 
the resting membrane potential (RMP), the half-width of action potential (AP), The AHP amplitude, the AP amplitude. AP amplitude was defined as the change in voltage from the RMP to the peak of AP and its duration was measured at mid amplitude. The AHP amplitude was measured from the RMP to the peak negativity after an AP and the duration was measured as the time required declining to $80 \%$ of its peak value. The firing regularity was assessed using the coefficient of variation (CV) of interspike intervals (ISI) of spontaneous activity (CV=ISI S.D / mean ISI).

\subsection{Plant material and drugs}

The aerial parts of Artemisia dracunculus were collected from the north of Iran in April (2006). A. dracunculus was authenticated by M. Kamalinejad and a voucher specimen (no. 861) was deposited in the herbarium of Faculty of Pharmacy, Shahid Beheshti University of Medical Sciences, Tehran. The plant materials were dried, far from direct sunlight. Then $1000 \mathrm{ml}$ of ethanol $(96 \%)$ was added to the dried leaves and kept at room temperature for $48 \mathrm{~h}$. Thereafter, it was filtered and the alcohol was evaporated using rotary evaporator and dried extract was obtained.

\subsection{Isolation of the essential oil}

The aerial parts of $A$. dracunculus were subjected to hydrodistillation for $3 \mathrm{~h}$ using a clevenger apparatus. The plant yielded $4 \%(\mathrm{v} / \mathrm{w})$ essential oil. The essential oil was kept protected from light at $4^{\circ} \mathrm{C}$ (Sayyah et al., 2004). The final concentrations of $0.1 \%$ and $0.005 \%$, required to influence the neuronal excitability for Tarragon extract and its essential oil, respectively, were chosen on the basis of the preliminary experiments.

Anethole $(0.99 \%)$ was purchased from Sigma (St. Louis, MO, USA), dissolved in Ringer solution and was applied at final concentrations of $0.5 \%$ and $2 \%$. Then the diluted anethole solution prepared in normal Ringer was perfused into the experimental chamber at a rate of approximately $2.5 \mathrm{ml} / \mathrm{min}$.

Pentylenetetrazol (PTZ, Sigma) was applied $(25 \mathrm{mM})$ into the bathing solution. Extract of Artemisia dracunculus was dissolved in absolute ethanol at a final concentration of $1 \%$ and $3 \%$ (the final concentration of vehicle in the perfusion solutions was $0.3 \%(\mathrm{v} / \mathrm{v})$. The same concentration of vehicle had no effect on bioelectrical activity of neurons. The $\mathrm{pH}$ of solutions was adjusted to 7.8 with either Trizma hydrochloride or Trizma base (Sigma). Each solution was superfused into the experimental chamber at a rate of approximately 2.5 $\mathrm{ml} / \mathrm{min}$.

\subsection{Statistical analysis}

Numerical results are given as mean \pm S.E.M., with $\mathrm{n}$ being the number of cells on which the measurement was done. Significant differences between the groups were evaluated using a student $t$-test or one way ANOVA and $\mathrm{P}<0.05$ was considered to be significant.

\section{Results}

\subsection{Tarragon essential oil altered the neuronal excitability more robust than its extract}

In normal Ringer, neurons showed spontaneous regularly spaced action potentials (Fig. 2) with a frequency of $0.9 \pm 0.05 \mathrm{~Hz}$ and a mean duration of $8.02 \pm 0.05 \mathrm{~ms}(\mathrm{n}=6$, Fig.3). 


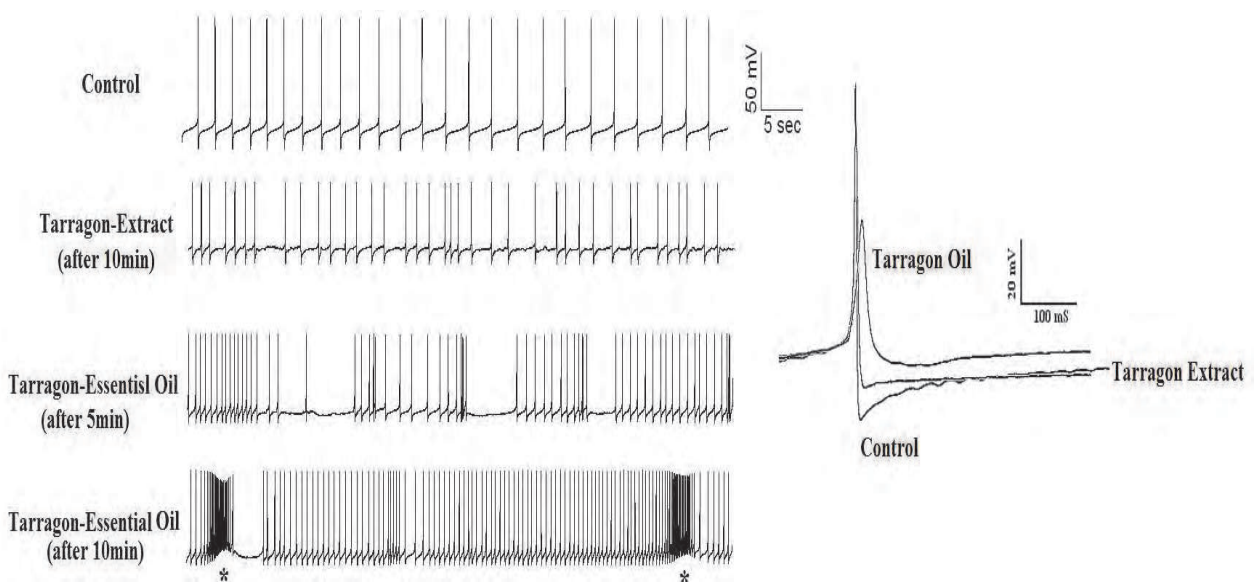

Fig. 2. Tarragon essential oil and its extract affect differentially F1 neuronal firing activity. (A) Spontaneous regular tonic firing activity in control condition. Application of Tarragon extract $(0.1 \%)$ caused an increase in the firing rate associated with an irregular discharge activity after $10 \mathrm{~min}(\mathrm{~B})$. However, Tarragon essential oil alone led to a neuronal hyperexcitability after $5 \mathrm{~min}$ (C) followed by a distinct PDS (asterisk) after 10min of application (D). The inset shows superimposed action potentials recorded in control and after treatment with either Tarragon essential oil or its extract alone.

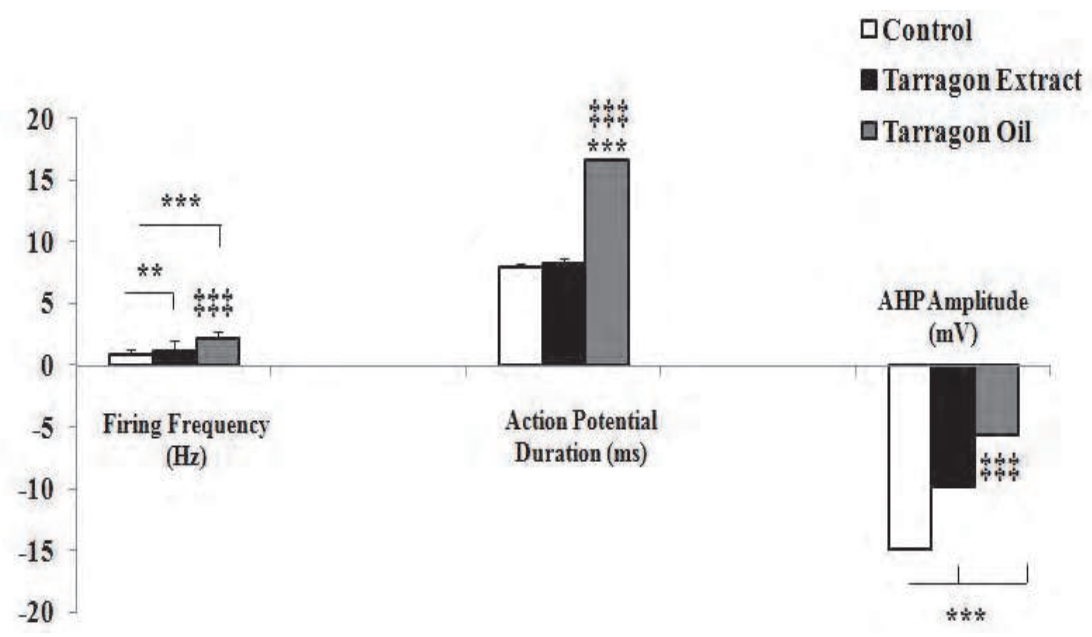

Fig. 3. Electrophysiological consequences of Tarragon application on action potential parameters in F1 neurons. Tarragon essential oil and its extract altered the AP configuration, as the essential oil profoundly increased the firing frequency and AP duration, but decreased the AHP amplitude. Tarragon extract also increased the firing rate and decreased the AHP, but to a lesser extent than did its essential oil. **, ***, significantly differences $(\mathrm{P}<0.01, \mathrm{P}<0.001)$ from controls and $\ddagger \ddagger \ddagger$, significant difference $(\mathrm{p}<0.001)$ from Tarragon extract treated group. 
Single action potentials were followed by AHP with mean amplitude of $-14.75 \pm 0.21 \mathrm{mV}$ (Fig. 3). When Tarragon essential oil was applied alone in the normal recording solution, within $10 \mathrm{~min}$ caused a significant increase in the firing frequency $(2.24 \pm 0.58 \mathrm{~Hz})$ compared to control and Tarragon extract $(1.28 \pm 0.3 \mathrm{~Hz}, \mathrm{P}<0.001)$, although exposure to the extract alone also produced a significant $(\mathrm{P}<0.01)$ increase in the excitability when compared to the normal excitability (Fig.3). Following addition of essential oil to normal Ringer solution, F1 neurons displayed a clear paroxysmal depolarization shift (PDS; Fig.2).Treatment with essential oil, furthermore, significantly resulted in a prolongation of action potentials $(16.61 \pm 0.11 \mathrm{~ms}, \mathrm{P}<0.001)$ both compared to control and extract alone $(8.35 \pm 0.14 \mathrm{~ms})$. However, there was no significant difference between the AP duration measured in control condition and after application of Tarragon extract (Fig. 3). Exposure to both Tarragon extract and essential oil caused a significant reduction in the AHP amplitude; however, this inhibitory effect was more profound in essential oil-treated neurons (Fig.3). Neither essential oil nor extract affected significantly the resting membrane potential of F1 cells $(-43.63 \pm 0.6 \mathrm{mV}$ in control; $-42.99 \pm 0.56 \mathrm{mV}$ and $-42.16 \pm 1.88 \mathrm{mV}$ in the presence of essential oil and extract, respectively).

\subsection{Tarragon extract, but not essential oil, attenuated the PTZ-induced hyperexcitability}

In order to investigate and compare the potential antiepileptic effects of Tarragon essential oil and its extract, PTZ $(25 \mathrm{mM})$ was added to the normal Ringer solution. Neuronal exposure to PTZ resulted in a significant increase in the spontaneous firing activity associated with a paroxysmal depolarization shift and bursting (Figs.4\&5A-A'). In addition, PTZ significantly increased the AP duration and decreased the AHP amplitude (Figs. 5B-B' and $\left.5 C-C^{\prime}\right)$. When, the essential oil of Tarragon was added to the Ringer solution containing PTZ, the firing frequency remained almost unchanged and even worsen the bursting activity, however the duration of AP and the amplitude of AHP were further significantly increased and decreased, respectively (Figs.4\&5A).

In contrast to these effects, treatment with Tarragon extract following PTZ application did not significantly affect the AP half-width (Fig. 5B'), but significantly decreased the firing frequency and the AHP amplitude (Figs.5 $\mathrm{A}^{\prime} \& \mathrm{C}^{\prime}$ ). Tarragon extract also caused the PTZinduced PDS to be disappeared and changed the burst activity into almost regular firing interrupted occasionally by a silent period associated with inhibitory postsynaptic potentials (IPSPs) (Fig.4).

\subsection{Anethole, one of the major components of the essential oil of Iranian} A. dracunculus, had differential effects on normal neuronal firing excitability

To characterize the electrophysiological consequences of neuronal exposure to anethole on normal excitability, a low $(0.5 \%)$ and a high $(2 \%)$ concentrations were chosen on the basis of our previous work (Ghasemi et al., 2011).

Application of $0.5 \%$ anethole did not significantly change the RMP, but at its higher concentration (2\%) hyperpolarized the cell resting membrane potential (data not shown) and altered the neuronal firing pattern from a regular spiking observed in control or in the presence of extract to an irregular hyperexcitable pattern often followed by a PDS (Fig.6). 


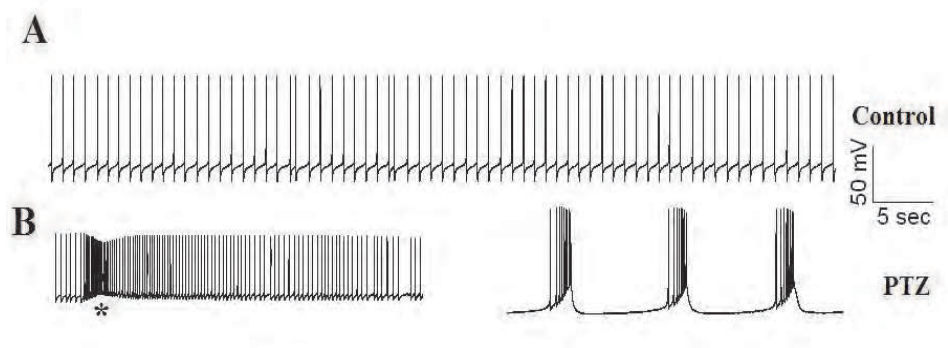

C

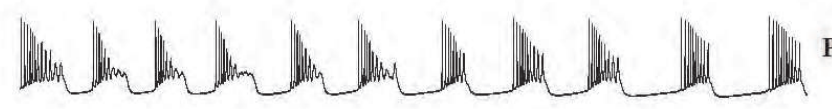

PTZ+Tarragon Essential Oil $0.005 \%$

D

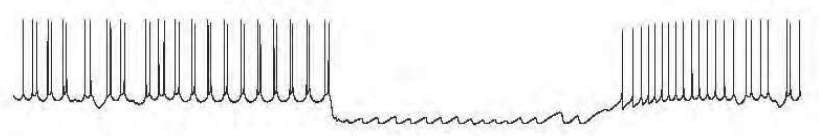

PTZ + Tarragon Extract $0.1 \%$

Fig. 4. Effects of Tarragon extract and essential oil on PTZ-induced epileptiform activity. (A) Spontaneous regular activity of a representative neuron under control condition. Following PTZ application, the cell became hyperexcitable and a PDS (asterisk) was appeared (B, left trace) and later the firing pattern was changed from tonic spiking to burst firing (B, right trace). Addition of Tarragon essential oil $(0.005 \%)$ in the presence of PTZ worsened the PTZinduced hyperexcitability and in this condition cell continued to exhibit burst firing (C). Tarragon extract at concentration of $0.1 \%$, however, decreased the PTZ-induced epileptiform activity and caused disappearance of PDS observed in the presence of PTZ alone. Neuronal firing was interrupted by IPSPs when normal Ringer containing PTZ+Tarragon extract was perfused.

Anethole at both concentrations resulted in a significant increase in the firing frequency, but to a much greater extent after $2 \%$ anethole (from $0.8 \pm 0.03 \mathrm{~Hz}$ in control condition to $3.11 \pm 0.09 \mathrm{~Hz}$ and $4.13 \pm 0.03 \mathrm{~Hz}$ after exposure to $0.5 \%$ and $2 \%$ anethole, respectively, Fig.7A). However, anethole at concentrations of $0.5 \%$ and $2 \%$ affected differently the discharge regularity, as evidenced by coefficient of variations $(\mathrm{CV})$ measured in different condition. Perfusion of normal Ringer containing anethole $0.5 \%$ slightly increased the firing irregularity $(\mathrm{CV}=0.22$ after anthole $0.5 \%$ versus 0.19 in control condition), whereas $2 \%$ 

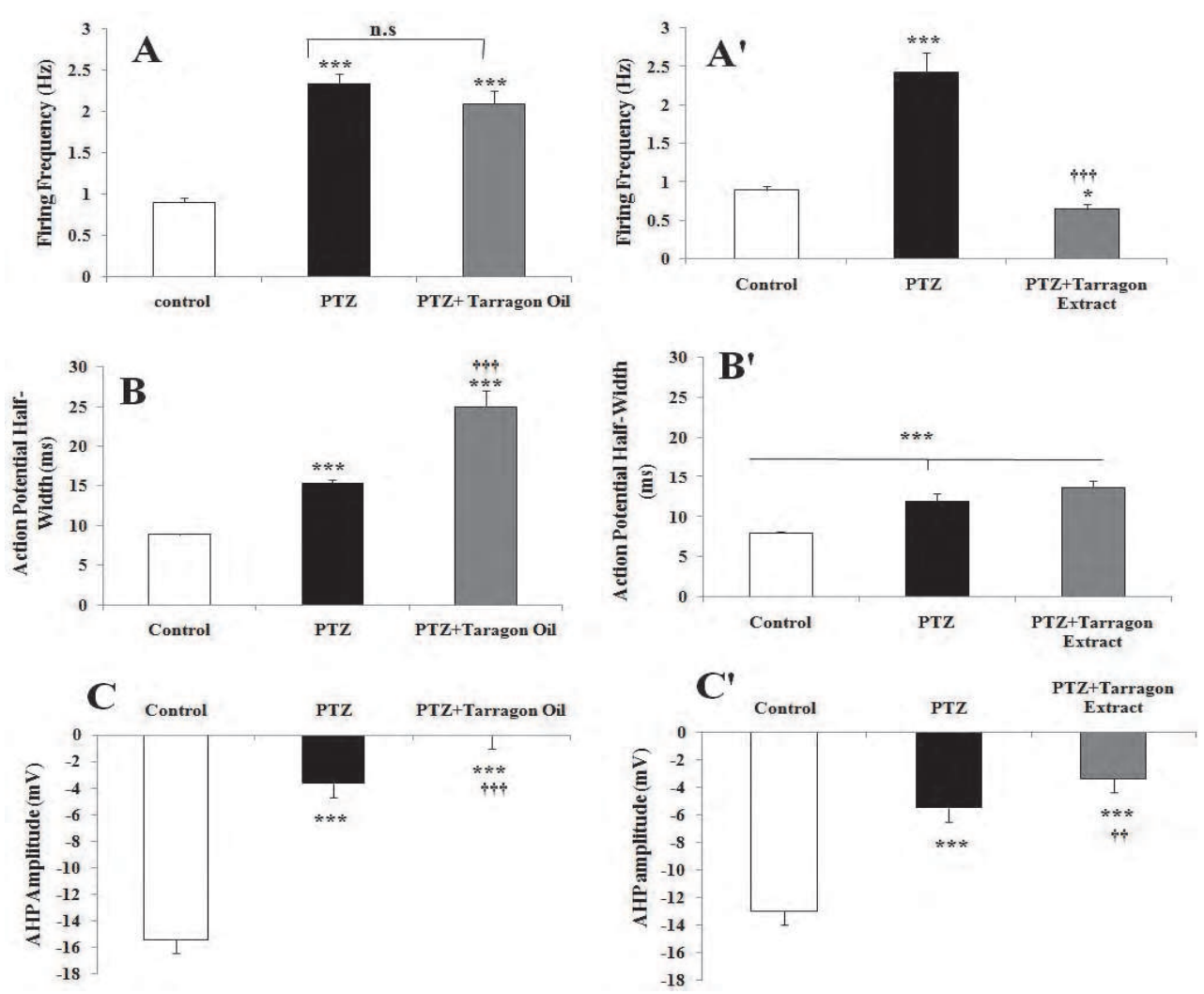

Fig. 5. The effect of anethole, the main constituent of Iranian A. Dracunculus, on firing activity of F1 neurons. Somatic conventional intracellular recording of spontaneous intrinsic firing F1 neuron in normal Ringer (A), after application of anethole at concentration of $0.5 \%$ (B) and following treatment with anethole $2 \%$ (C). Application of anethole at higher concentration clearly caused a neuronal excitability and elicited a PDS (asterisk).

anethole increased the firing precision as defined by smaller CV (0.03). Furthermore, anethole induced differential effect on the AHP that followed AP. At concentration of $0.5 \%$ it caused a significant reduction in the AHP amplitude, but at $2 \%$ produced a significant increase in the AHP, both compared to control and anethole $0.5 \%$ (Fig. 7C). Both high and low concentrations of anethole caused also a significant shortening of AP compared to control group, although this effect was more potent in $2 \%$ anethole-treated group when compared with $0.5 \%$ anethole (Fig.7B). 


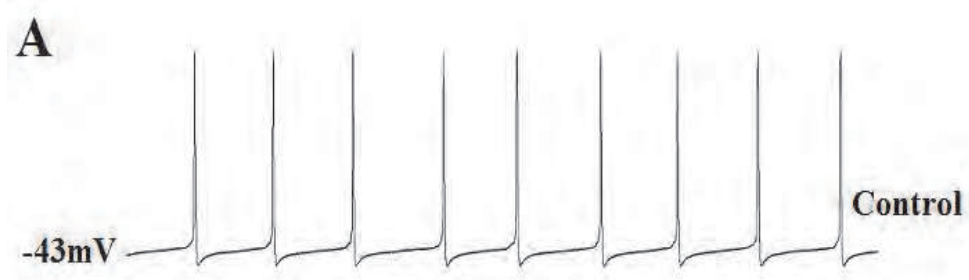

B
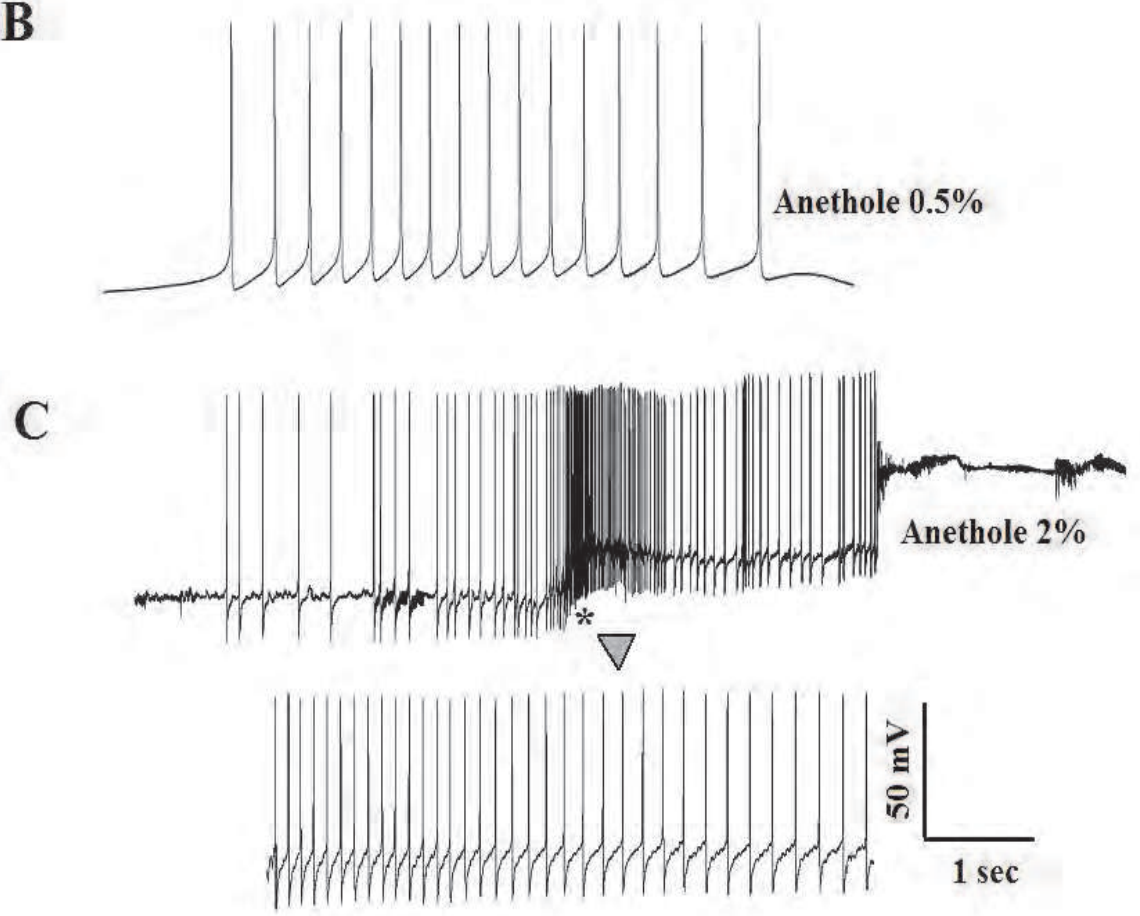

Fig. 6. The effect of anethole, the main constituent of Iranian A. Dracunculus, on firing activity of F1 neurons. Somatic conventional intracellular recording of spontaneous intrinsic firing F1 neuron in normal Ringer (A),fter application of anethole at concentration of $0.5 \%$ (B) and following treatment with anethole $2 \%$ (C). Application of anethole at higher concentration clearly caused a neuronal excitability and elicited a PDS (asterisk). 


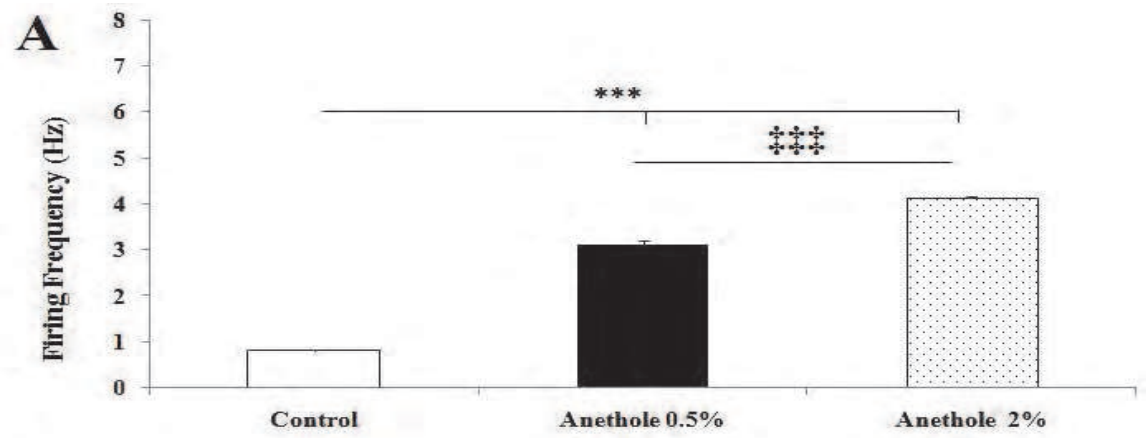

B

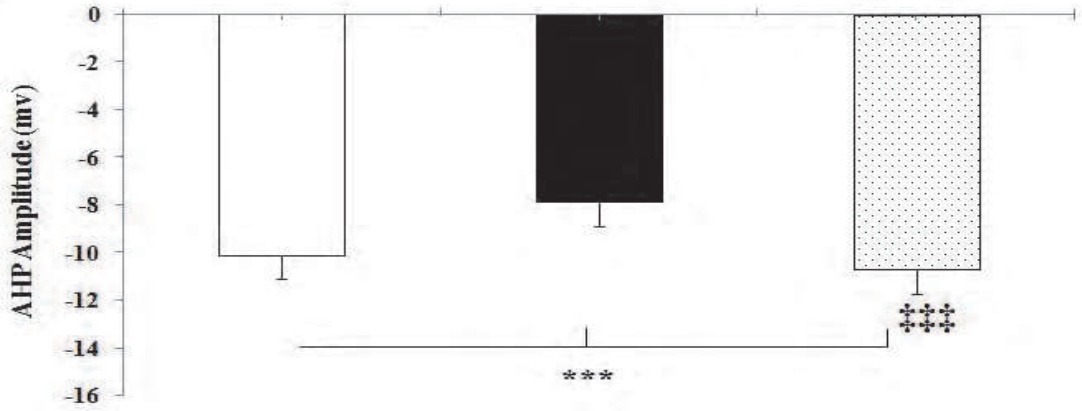

C

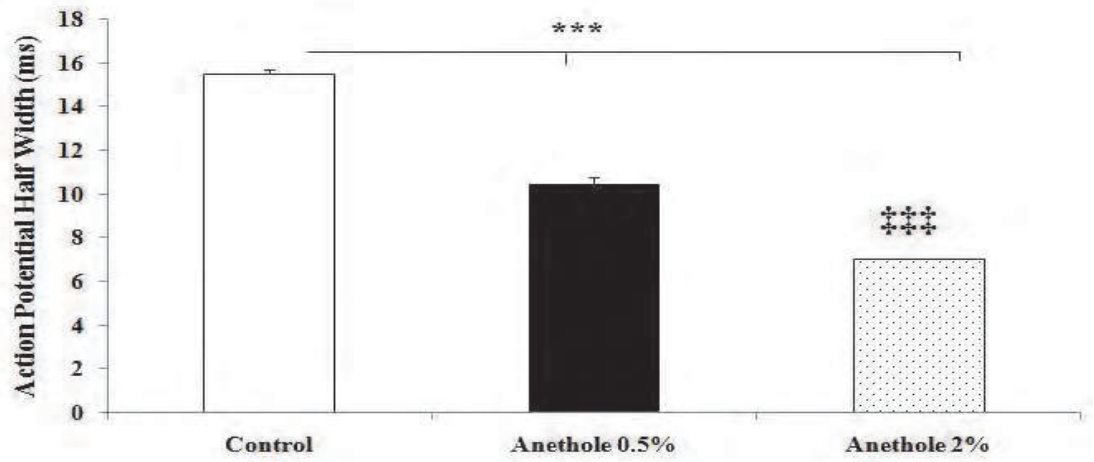

Fig. 7. Effects of anethole treatment on action potential characteristics. Effects of anethole treatment on (A) firing frequency, AHP amplitude (B) and on the AP duration (C). ***, significantly different $(\mathrm{P}<0.001)$ from control; 㧊, significant different $(\mathrm{P}<0.001)$ from the $0.5 \%$ anethole- treated group. 


\section{Discussion}

Invertebrates have often been used as an experimental model for investigating the cellular mechanisms of the effect of many convulsant and anticonvulsant agents. It has been reported that convulsant drugs such as PTZ induces a potential pattern in molluscan neurons which closely resembles the epileptic activity of mammalian neurons, called PDS (Goldensohn and Pupura, 1963; Matsumoto and Ajmone Marsan, 1964; Sugaya et al., 1973). In invertebrate neurons, following application of PTZ, the endogenous mechanisms are so pronounced that PDS may still be recorded even after complete inhibition of synaptic inputs (Faugier-Grimaud, 1974; Speckmann and Caspers, 1973). Ion channel currents underlying action potentials have been shown to participate in the generation of epileptic discharges as well as in the actions of antiepileptic drugs. Among these channels, calcium and voltagedependent $\mathrm{K}+$ channels play a crucial in the repolarization and hyperpolarization that follows PDSs. The knowledge of the cellular mechanisms of action of the medicinal plants with antiepileptic potential is allowing the design of new therapeutic approaches possibly with fewer side effects. Aromatic spice plants have been used traditionally as food and for medicinal purposes in the therapy of some diseases for a long time in the world. Essential oils and extracts in these plants are used extensively in medicine and in the food and cosmetic industries. Although, there is a distinct difference between pure essential oils and simple plant extracts, the mechanisms of these at the cellular level have not been completely elucidated yet. As an aromatic plant, Tarragon (A. dracunculus anisum L.) is a perennial herb in the family Asteraceae that exerts several therapeutic effects.

In traditional medicine, the fruit and dried aerial parts of Tarragon were used as a treatment for epilepsy, toothache and diarrhea (Zargari, 1989). The plant is mildly sedative (Sayyah et al., 2004) and has been taken to aid sleep (Chevallier, 1996). Recently, the anticonvulsive activity of essential oil of Artemisia dracunculus in a rat model of epilepsy has been shown. It is reported that the monoterpenoids especially trans-anethole, pinene and methyl eugenol present in the essential oil, mediates its anticonvulsant activity (Sayyah et al., 2004).

The present study compared the electrophysiological consequences of Tarragon essential oil and its extract alone and on the PTZ-induced epileptiform activity. Moreover, alterations in the parameters of the action potentials upon application of anethole as a major component of Iranian Tarragon on neuronal cells were also investigated. In our previous work we reported that the fruit essential oil of Pimpinella anisum L. (Umblliferae), which contains anethole, not only did not show antiepileptic activity but also induced neuronal hyperexcitability (Janahmadi et al., 2008). On the other hand, we have also showed that both the essential oil of cuminum cyminum and low concentration $(0.05 \%)$ of Tarragon extract exhibit antiepileptic activity (Janahmadi et al., 2006; Farajnia et al., 2011).

The results obtained here showed that the essential oil of Tarragon not only does not show any antiepileptic activity at concentration of $0.005 \%$, but also worsened the epileptiform activity induced by PTZ. Whereas, Tarragon extract, at even higher concentration $(0.1 \%)$ than that we have reported more recently, can reduce and modulate PTZ-induced neuronal hyperexcitability. Furthermore, the finding showed that anethole affects the normal neuronal excitability in a concentration manner. The neuronal excitability and the firing patterns are balanced by the activity of many ion channels, including voltage and $\mathrm{Ca}^{2+}$-activated $\mathrm{K}^{+}$(SK and BK) channels (Faber et al., 2005; Crest and Gola, 1993; Arai et al., 2004). 
Here, it was found that both essential oil and extract of $A$. dracunculus led to a decrease in the amplitude of AHPs and the essential oil, but not extract prolonged the AP duration. In snail neurons, spike duration and AHP amplitude are determined by a set of potassium channels which underlie fast and delayed outward $\mathrm{K}^{+}$currents (Bal et al. 2000; Sakakibara et al. 2005; Solntseva 1995; Thompson 1977). There are also two classes of $\mathrm{Ca}^{2+}$ activated $\mathrm{K}^{+}$channels $\left(\mathrm{K}_{\mathrm{Ca}}\right)$; the large conductance $\mathrm{Ca}^{2+}$ activated $\mathrm{K}^{+}$channels ( $\mathrm{BK}$ channels) and the small conductance $\mathrm{Ca}^{2+}$ activated $\mathrm{K}^{+}$channels (SK) (Crest and Gola 1993; Hermann and Erxleben 1987). SK channels mediate a $\mathrm{Ca}^{2+}$-activated afterhyperpolarizing current, $\mathrm{I}_{\mathrm{AHP}}$, in most nerve cells, whereas large conductance $\mathrm{Ca}^{2+}$-activated $\mathrm{K}^{+}(\mathrm{BK})$ channels are responsible for the fast afterhyperpolarization (fAHP). Both types of channels are activated during the action potential causing a transient hyperpolization of the cell membrane. This produces the AHP which in turn inhabits further AP firings. Therefore, the decrease in AHP and the increase in the firing rate particularly in the presence of Tarragon essential oil could be partly related to the possible inhibition of $\mathrm{K}_{\mathrm{Ca}}$ channels. However, the increase in the duration of AP following Tarragon oil treatment might be due to the inhibition of $\mathrm{Na}^{+}$and/or voltage-gated $\mathrm{K}^{+}$channels. It has now been reported that very small influxes of $\mathrm{Na}^{+}$through voltage-gated $\mathrm{Na}^{+}$channels activate a $\mathrm{K}^{+}$ conductance which play an important role in determining AP duration in both vertebrate and invertebrate neurons (Bader et al.,1985; Hartung, 1985; Dryer et al., 1989; Budelli et al., 2009).

On the other hand, the results of the second sets of the experiments suggest that Tarragon extract has a potential antiepileptic effect. The decrease in the PTZ-induced hyperexcitability, the unchanged AP duration and the pause between active periods clearly indicate that the crude extract of Tarragon can alleviate the epileptiform activity partly through the activation of $\mathrm{K}^{+}$channels or receptor dependent ion channels.

It has been reported that epileptic activity can be suppressed by drugs that enhance gamma amino butyric acid-type $\mathrm{A}\left(\mathrm{GABA}_{\mathrm{A}}\right)$ receptor-mediated inhibitory neurotransmission, such as benzodiazepines and phenobarbital (Macdonald and Kelly, 1995). The presence of anticonvulsant benzodiazepines in alcoholic extract of A. dracunculus supports the antiepileptic potential of extract (Kavvadias et al., 2000). The appearance of IPSPs during quiescence period recorded between firing activity in the presence of Tarragon extract, therefore, could be due to the activation of $\mathrm{GABA}_{\mathrm{A}}$ receptors. However, Tarragon essential oil worsened the PTZ-induced profound hyperexcitability, as evidenced by a significant increase in the firing frequency and reduction in the AHP amplitude. The stronger antiepileptic activity of Tarragon alcoholic extract than its own essential oil could be attributed to the benzodiazepine in the extract (Kavvadias et al., 2000), as we have more recently reported that picrotoxin, a GABA antagonis, eliminates the IPSPs-induced by Tarragon extract at concentration of $0.05 \%$ (Farajnia et al., 2011). However, potentiation of PTZ-induced epileptiform activity possibly could be due, in part, to the existence of some active component, such as anethole. In the present study, we found that anethole at higher concentration $(2 \%)$, but not at lower concentration $(0.5 \%)$ produces hyperexcitability and paroxysmal depolarization shift very similar to that of induced by PTZ in $\mathrm{Na}^{+}$Ringer solution. We have more recently demonstrated that anethole affects the $\mathrm{Ca}^{2+}$-dependent excitability and $\mathrm{Ca}^{2+}$ spike characteristics in a concentration manner (Ghasemi et al., 2011). Therefore, it can be speculated that anethole $2 \%$ increases the neuronal hyperexcitability directly or in directly through activation of outward $\mathrm{K}^{+}$channels, including $\mathrm{K}_{\mathrm{Ca}}$ as 
evidenced by a significant increase and decrease in the AP duration and AHP amplitude, respectively.

The stronger antiepileptic activity of alcoholic extract of Tarragon than its own essential oil could be attributed to the benzodiazepine in the extract (Kavvadias et al., 2000), as we have more recently reported that picrotoxin, a GABA antagonist, eliminates the IPSPs-induced by 0.05\% Tarragon extract (Farajnia et al., 2011). However, potentiation of PTZ-induced epileptiform activity by essential oil possibly could be due to the existence of some active component, such as anethole. In the present study, we found that anethole at higher concentration $(2 \%)$, but not at lower concentration $(0.5 \%)$ produces hyperexcitability and paroxysmal depolarization shift very similar to that of induced by PTZ in $\mathrm{Na}^{+}$Ringer solution. Anethole treatment at concentration of $2 \%$ enhances the AHP amplitude which in turn hyperpolarizes the cell membrane and thereby removes sodium channels inactivation and increases the availability of these channels. The availability of $\mathrm{Na}^{+}$channel, which is strongly regulated by AHP-induced hyperpolarization, is known to regulate the firing regularity and increases the firing excitability (Patlak, 1991; Vervaeke et al., 2006; Mecer et al., 2007).

It is likely the augmentation of the amplitude of AHP following treatment with anethole $2 \%$ could be caused by activation of voltage and/or particularly calcium dependent potassium channels, which play an important role in neuronal discharge regularity. it is generally accepted that AHP amplitude is reversely correlated with the firing frequency (Madison and Nicoll, 1984; Hallworth et al., 2003; Vatanparast and Janahmadi, 2009) and blockade of these channels disrupts the precision of firing and produces less regularity in firing (Haghdoust et al., 2007; Hallworth et al., 2003; Sausbier et al., 2004; Walter et al., 2006). Therefore, increasing the firing precision and regularity, as evidenced by a significant increase in the AHP amplitude and a decrease in CV following exposure to $2 \%$ anethole here in F1 cells, could be possibly attributed to the opening of $\mathrm{K}_{\mathrm{Ca}}$ channels.

We have more recently demonstrated that anethole affects the $\mathrm{Ca}^{2+}$-dependent excitability and $\mathrm{Ca}^{2+}$ spike characteristics in a concentration manner (Ghasemi et al., 2011).

In conclusion, findings of the study suggest that herbal medicine may be considered a s a two-edged sword since some of the medicinal essential oils (such as anise and Tarragon oils) and the compounds isolated from them (e.g. anehole) have potential capacity to induce neuronal hyperexcitability and epileptiform activity or alternatively their own crude extracts may possess antiepileptic activity. Therefore, when they are used for treating patients suffer from epilepsy, a certain caution is needed.

\section{References}

Al-Harbi MM, Qureshi S, Raza M, Ahmed MM, Giangreco AB, Shah AH. (1995). Influence of anethole treatment on the tumour induced by Ehrlich ascites carcinoma cells in paw of Swiss albino mice. Eur J Cancer Prev 4 : 307-318.

Aqili Khorasani, MH. (1992). Makhzan al adviah. Safa publication, Tehran, pp 583-584.

Arai H, Kubo T, Nagahama T. (2004). Modulation of a feeding neural circuit by microinjection of $\mathrm{K}+$ channel expression genes into a single identified neuron in Aplysia kurodai. Zoolog Sci 21(4):369-373.

Bader CR, Bernheim L, Bertrand D. (1985). Sodium-activated potassium current in cultured avian neurones. Nature 317: 540-542. 
Bal R , Janahmadi M , Green GGR, Sanders DJ. (2000). Effect of calcium channel blockers on transient outward current of F76 and D1 neuronal soma membrane in the subesophageal ganglion of Helix aspersa. J Membr Biol 173:179-185.

Boissier JR, Simon P, Le Bourhis B. (1967). Experimental psychotropic action of cis and trans isomers of anethol. Therapie $22: 309-323$.

Budelli G, Hage TA, Wei A, Rojas P, Jong YJ, O'Malley K, Salkoff L. (2009). Na+-activated K+ channels express a large delayed outward current in neurons during normal physiology. Nat Neurosci 12(6):745-570.

Chainy GB, Manna SK, Chaturvedi MM, Aggarwal BB. (2000). Anethole blocks both early and late cellular responses transduced by tumor necrosis factor: effect on NF-kB, AP-1, JNK, MAPKK and apoptosis. Oncogene 19 (25) : 2943-2950.

Chevallier, A. (1996). The Encyclopedia of Medicinal Plants Dorling Kindersley, London.

Crest M , Gola M. (1993). Large conductance $\mathrm{Ca}^{2+}$-activated $\mathrm{K}^{+}$channels are involved in both spike shaping and firing regulation in Helix neurones. J Physiol 465:265-287.

Dryer SE, Fujii JT, Martin AR. (1989). $\mathrm{Na}^{+}$-activated $\mathrm{K}^{+}$current in cultured brain stem neurones from chicks. J Physiol 410:283-296.

Faber ESL, Delaney AJ, Sah P. (2005). SK channels regulate excitatory synaptic transmission and plasticity in the lateral amygdala. Nat Neurosci 8:635-641.

Farajnia S, Janahmadi M, Vatanparast J, Abbasipour H, Kamalinejad M. (2011). The Electrophysiological Consequences of Artemisia dracunculus L. (Tarragon) Extract on Pentylenetetrazol-Induced Epileptiform Activity in Snail Neurons. Cell J (Yakhteh), 12 (4): 495-502.

Faugier-Grimaud S. (1974). Extrasynaptic mechanisms of cardiazol-induced epileptiform activity of invertebrate neurons. Brain Res 69: 354-360.

Freire RS, Morais SM, Catunda-Junior FE, Pinheiro DC. (2005). Synthesis and antioxidant, anti-inflammatory and gastroprotector activities of anethole and related compounds. Bioorg Med Chem13 (13): 4353-4358.

Ghasemi Z, Hassanpour-Ezatti M, Kamalinejad M, Janahmadi M. (2011). Functional involvement of $\mathrm{Ca}(2+)$ and $\mathrm{Ca}(2+)$-activated $\mathrm{K}(+)$ channels in anethol -induced changes in $\mathrm{Ca}(2+)$ dependent excitability of $\mathrm{F} 1$ neurons in Helix aspersa. Fitoterapia. 82 (5):750-756.

Ghelardini C, Galeotti N, Mazzanti G. (2001).Local anaesthetic activity of monoterpenes and phenylpropanes of essential oils. Planta Medica 67 : 564-566.

Goldensohn ES, Pupura DP. (1963). Intracellular potentials of cortical neurons during focal epileptogenic discharges. Science 139: 840-842.

Gülçın I, Oktay M, Kıreçcı E, Küfrevıoglu ÖI. ( 2003). Screening of antioxidant and antimicrobial activities of anise (Pimpinella anisum L.) seed extracts. Food Chem 83:371-382.

Haghdoust H, Janahmadi M, Behzadi G. (2007). Physiological role of dendrotoxin-sensitive $\mathrm{K}^{+}$channels in the rat cerebellar Purkinje neurons. Physiol Res 56: 807-813.

Hallworth N E, Wilson C J , Bevan M D. (2003). Apamin-sensitive small conductance calcium-activated potassium channels, through their selective coupling to voltagegated calcium channels, are critical determinants of the precision, pace, and pattern of action potential generation in rat subthalamic nucleus neurones in vitro. $J$ Neurosci 23:7525-7542. 
Hartung K. (1985). Potentiation of a transient outward current by $\mathrm{Na}+$ influx in crayfish neurones. Pfluigers Archiv 404: 41-44.

Hermann A, Erxleben C. (1987). Charybdotoxin selectively blocks small Ca-activated K channels in Aplysia neurons. J Gen Physiol 90:27-47.

Janahmadi M, Niazi F, Danyali S, Kamalinejad M. (2006). Effects of the fruit essential oil of Cuminum cyminum Linn. (Apiaceae) on pentylenetetrazol-induced epileptiform activity in F1 neurones of Helix aspersa. J Ethnopharmacol 104(1-2):278-282.

Janahmadi M, Farajnia S, Vatanparast J, Abbasipour H, Kamalinejad M. (2008). The fruit essential oil of Pimpinella anisum L. (Umblliferae) induces neuronal hyperexcitability in snail partly through attenuation of after-hyperpolarization. J Ethnopharmacol 120(3):360-365.

Kavvadias D, Abou-Mandour AA, Czygan FC, Beckmann H, Sand P, Riederer P, Schreier P. (2000). Identification of benzodiazepines in Artemisia dracunculus and Solanum tuberosum rationalizing their endogenous formation in plant tissue. Biochem Biophys Res Commun 5;269(1):290-295.

Kerkut GA, Lambert JDC, Gayton RJ, Loker JE, Walker RJ. (1975). Mapping of nerve cells in the sub-oesophageal ganglia of Helix aspersa. Comp Biochem Physiol (A) 50:1-25.

MacDonald RL, Kelly KM. (1995). Antiepileptic drug mechanisms of action. Epilepsia 36: 502-512.

Madison DV, Nicoll RA. (1984). Control of the repetitive discharge of rat CA 1 pyramidal neurones in vitro. J Physiol 354:319-331.

Matsumoto H , Ajmone Marsan C. (1964). Cortical cellular phenomen in experimental epilepsy: interictal manifestations. Exp Neurol 9: 286-304.

Meepagala KM, Sturtz G, Wedge DA. (2002). Antifungal constituents of the essential oil fraction of Artemisia dracunculus L. Var. dracunculus. J Agr Food Chem 50: 6989-6992.

Parejo I, Viladomat F, Bastida J, Rosas-Romero A, Flerlage N, Burillo J, Codina C. (2002). Comparison between the radical scavenging activity and antioxidant activity of six distilled and nondistilled. Mediterranean herbs and aromatic plants. J Agr Food Chem 50: 6882-6890.

Patlak, J B. (1991) Molecular kinetics of voltage-dependent $\mathrm{Na}^{+}$channels. Physiol Rev 71:1047-1080

Sakakibara M, Okuda F, Nomura K, Watanabe K, Meng H, Horikoshi T, Lukowiak K. (2005) Potassium currents in isolated statocyst neurons and RPeD1 in the pond snail, Lymnaea stagnalis. J Neurophysiol 94:3884-92.

Sausbier M, Hu H, Arntz C, Feil S, Kamm S, Adelsberger H, Sausbier U, Sailer CA, Feil R, Hofmann F, Korth M, Shipston MJ, Knaus HG, Wolfer DP, Pedroarena CM, Storm JF, Ruth P. (2004), Cerebellar ataxia and Purkinje cell dysfunction caused by $\mathrm{Ca}^{2+}$ activated $\mathrm{K}^{+}$channel deficiency. Proc Natl Acad Sci U S A. 101:9474-9478.

Sayyah M, Nadjafnia L, Kamalinejad M .(2004). Anticonvulsant activity and chemical composition of Artemisia dracunculus L. essential oil. J Ethnopharmcol 94: 283-287.

Singh G, Kapoor IPS, Pandey SK, Singh UK, Singh RK. (2002). Studies of essential oils. Part 10. Antibacterial activity of volatile oils of some spices. Phytother Res 16 (7), 680-682.

Soliman KM, Badeaa RI. (2002). Effect of oil extracted from some medicinal plants on different mycotoxigenic fungi. Food ChemToxicol 40 (11): 1669-1675. 
Solntseva EI (1995). Properties of slow early potassium current in neurons of snail Helix pomatia. Gen Pharmacol 26:1719-1726.

Speckmann EJ, Caspers H. (1973). Proxysmal depolarization and changes in action potentials induced by pentylenetetrazol in isolated neurons of Helix pomatia. Epilepsia 14: 397-408.

Sugaya A, Sugaya E, Tsujitani M. (1973). Pentylenetetrazol-induced intracellular potential changes of the neuron of the Japanese land snail Euhadra peliomphala. Jpn J Physiol 23: 261-274.

Taylor PS (1987) Selectivity and patch measurements of A-current channels in Helix aspersa neurones. J Physiol 388:437-447.

Thompson SH.(1977).Three pharmacologically distinct potassium channels in molluscan neurones. J Physiol 265:465-488.

Vatanparast J, Janahmadi M. (2009). Contribution of apamin-sensitive SK channels to the firing precision but not to the slow afterhyperpolarization and spike frequency adaptation in snail neurons. Brain Res 1255: 57-66.

Vervaeke K, Hu H, Graham LJ, Storm JF. (2006). Contrasting effects of the persistent Na+ current on neuronal excitability and spike timing. Neuron 49: 257-270.

Walter JT, Alviña K, Womack MD, Chevez C, Khodakhah K. (2006). Decreases in the precision of Purkinje cell pacemaking cause cerebellar dysfunction and ataxia. Nat Neurosci 9:389-397.

Zani F, Massimi G, Benvenuti S, Bianchi A, Albasini A, Melegari M, Vampa G, Bellotti A, Mazza P. (1991). Studies on the genotoxic properties of essential oils with Bacillus subtilis re-assay and Salmonella/microsome reversion assay. Planta Medica 57: 237241.

Zargari A. (1989). Medicinal Plants, 2. Tehran University, Tehran. 


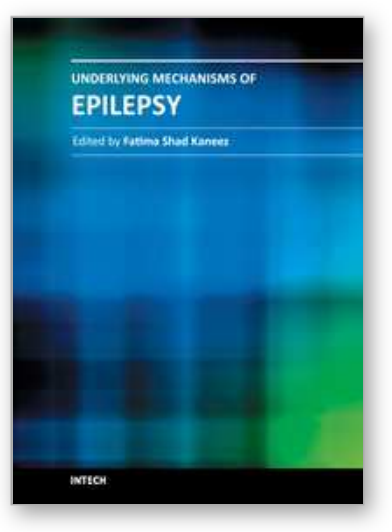

\author{
Underlying Mechanisms of Epilepsy \\ Edited by Prof. Fatima Shad Kaneez
}

ISBN 978-953-307-765-9

Hard cover, 354 pages

Publisher InTech

Published online 26, September, 2011

Published in print edition September, 2011

This book is a very provocative and interesting addition to the literature on Epilepsy. It offers a lot of appealing and stimulating work to offer food of thought to the readers from different disciplines. Around $5 \%$ of the total world population have seizures but only $0.9 \%$ is diagnosed with epilepsy, so it is very important to understand the differences between seizures and epilepsy, and also to identify the factors responsible for its etiology so as to have more effective therapeutic regime. In this book we have twenty chapters ranging from causes and underlying mechanisms to the treatment and side effects of epilepsy. This book contains a variety of chapters which will stimulate the readers to think about the complex interplay of epigenetics and epilepsy.

\title{
How to reference
}

In order to correctly reference this scholarly work, feel free to copy and paste the following:

Mahyar Janahmadi, Sahar Farajnia, Zahra Ghasemi and Ali Rastgar (2011). Medicinal Herbs and Epilepsy: A Two Edged Sword, Underlying Mechanisms of Epilepsy, Prof. Fatima Shad Kaneez (Ed.), ISBN: 978-953-307765-9, InTech, Available from: http://www.intechopen.com/books/underlying-mechanisms-ofepilepsy/medicinal-herbs-and-epilepsy-a-two-edged-sword

\section{INTECH}

open science | open minds

\section{InTech Europe}

University Campus STeP Ri

Slavka Krautzeka 83/A

51000 Rijeka, Croatia

Phone: +385 (51) 770447

Fax: +385 (51) 686166

www.intechopen.com

\section{InTech China}

Unit 405, Office Block, Hotel Equatorial Shanghai

No.65, Yan An Road (West), Shanghai, 200040, China

中国上海市延安西路65号上海国际贵都大饭店办公楼405单元

Phone: +86-21-62489820

Fax: +86-21-62489821 
(C) 2011 The Author(s). Licensee IntechOpen. This chapter is distributed under the terms of the Creative Commons Attribution-NonCommercialShareAlike-3.0 License, which permits use, distribution and reproduction for non-commercial purposes, provided the original is properly cited and derivative works building on this content are distributed under the same license. 